\title{
The Relationship between Subjective Sleep, Emotions, Social Support and Excessive Daytime Sleepiness in Female Undergraduate Students
}

\author{
Jiyoung Lee, Sooyeon Suh \\ Department of Psychology, Sungshin University, Seoul, Korea \\ 여자 대학생의 주간과다졸림증과 주관적 수면, 정서, 사회적 지지 간의 관계 \\ 이지영, 서수연 \\ 성신여자대학교 심리학과
}

Received April 26, 2017

Revised June 24, 2017

Accepted June 26, 2017

Address for correspondence

Sooyeon Suh, $\mathrm{PhD}$

Department of Psychology,

Sungshin University,

2 Bomun-ro 34da-gil,

Seongbuk-gu, Seoul 02844, Korea

Tel: $+82-2-920-7215$

Fax: +82-2-920-2040

E-mail: alysuh@sungshin.ac.kr

Objectives: The current study aimed to explore the relationship between subjective sleep, emotions, social support and excessive daytime sleepiness (EDS), and extract the strongest predictor of EDS in female undergraduate students. Methods: Our subjects consisted of 168 female undergraduate students (mean age 21.64 \pm 1.66 ). All participants completed Epworth Sleepiness Scale (ESS), Insomnia Severity Index, Hospital Anxiety and Depression Scale, Social Support Scale, and the Munich Chronotype Questionnaire. Results: There were significant associations between insomnia, anxiety, depression with EDS, but not with subjective total sleep time of workdays and freedays. Also, 23.8\% $(n=40)$ of subjects endorsed clinical levels of EDS (ESS $>10)$. Insomnia, anxiety, and depression were higher, and social support was lower in the EDS group compared to the normal group. Finally, we explored factors that influenced EDS, resulting in anxiety and social support being the strongest predictors of EDS. Social support was the strongest predictor of EDS compared to other predictors $(\beta=-0.276, p<0.001)$. Conclusions: Results suggest that social support may be important to consider in female undergraduate students who experience EDS.

J Sleep Med 2017;14(1):36-42

Key Words: Excessive daytime sleepiness, Sleep, Insomnia, Anxiety, Depression, Social support.

서 론

주간과다졸림증(excessive daytime sleepiness)이란 낮 시 간에 과도한 졸림을 경험하며 깨어 있기 위한 노력을 함에도 불구하고 각성 상태를 유지하기 힘든 증상이다. ${ }^{1}$ 보통 일반 적인 졸림은 생리적인 평가와 일치하지만, 주간과다졸림증 은 생리적인 평가와 일치하지 않는 행동적이고 주관적인 졸 림이라는 점에서 다르다고 알려져 있다. ${ }^{2}$ 성인의 주간과다졸 림증은 2002년 9.8\%에서 2012년 12.7\%로 점차 증가하였으며, Lund 등의 연구에 따르면 대학생의 $75 \%$ 가 주간과다졸림증 을 흔히 경험하는 것으로 나타났다. ${ }^{3,4}$

This is an Open Access article distributed under the terms of the Creative Commons Attribution Non-Commercial License (http://creativecommons.org/licenses/by-nc/4.0) which permits unrestricted non-commercial use, distribution, and reproduction in any medium, provided the original work is properly cited.
대학생은 후기 청소년기에서 초기 성인기 사이에 해당하며, 이 시기에는 생물학적으로 지연된 수면 위상을 보이고 졸림 에 대한 취약성이 증가하는 것으로 알려져 있다. ${ }^{5}$ 특히 대학 생은 고등학생보다 더 지연된 수면 양상을 보이는데, 이는 청 소년기에서 성인기로 전환하면서 학업적, 사회적 요구가 점 차 증가하기 때문에 밤 늦게까지 각성을 유지해야 하는 환경 적인 요소가 추가적으로 영향을 미치는 것으로 보고되었다. ${ }^{4}$ 이에 더해 여성은 생물학적인 이유에서(뇌 구조에서의 성차) 남성보다 수면 양상의 변화에 영향을 더 받고 수면과 관련된 불편감을 많이 호소하는 것으로 알려져 있다. ${ }^{6}$ 또한, 수면 시 간에 차이가 없을 경우에도 여성이 남성에 비해 주관적인 수 면장애 증상이나 수면 부족을 더 호소하였고, 주간과다졸림 증의 비율도 약 2 배가량 높은 경향을 보였다. 7,8

주간과다졸림증의 원인은 다양하고, 그 중에서도 임상군은 
수면 문제와 밀접한 관련이 있다고 알려져 왔다. 예를 들어, 수면장애에서 폐쇄성 수면무호흡증 환자들은 흔히 과도한 주 간과다졸림증을 보고한다. 그렇지만 주간과다졸림증과 밀접 한 관련성이 있다고 밝혀진 수면장애는 젊은 성인들에게는 유병률이 높지 않기 때문에, 젊은 대학생들 사이에서는 주간 과다졸림증의 원인이 수면 양상에만 국한되어 있지 않다. 물 론 일반적으로 수면 부족이 주간과다졸림증을 발생시키는 것 으로 가장 많이 알려져 있고, 수면 박탈을 통해 의도적인 수면 부족 상태를 만들면 주간에 졸림을 경험한다는 여러 연구 결 과가 이를 뒷받침했다. 2,9 그러나 최근 성인의 주간과다졸림 증 관련 요인을 탐색한 결과, 수면 시간 자체보다 수면 시간에 대한 개인의 주관적인 지각이 주간과다졸림증과 관련 있는 요인으로 나타났다. 또한, 수면 부족보다는 불면증이나 우울, 수면에 대한 만족도와 같은 심리적 요인이 주간과다졸림증 에 영향을 미쳤다고 보고되어, 주간과다졸림증의 수면 양상 및 원인에 대한 새로운 관점이 제시되었다. ${ }^{10}$

Nugent 등의 연구에서 불면증 환자의 $28.1 \%$ 가 주간과다 졸림증을 동반하였으며, ${ }^{11}$ 불면증의 하위 증상과 수면제 사 용이 주간과다졸림증의 위험 요인이었다. ${ }^{1213}$ 또한 우울증의 약 $57.1 \%,{ }^{14}$ 불안장애의 약 $19.4 \%$ 가 주간과다졸림증을 동반하였 고, 주간과다졸림증은 우울증의 지속기간, 불안장애의 심각도 와 관련이 있었다. ${ }^{13,15}$

심리적인 요인 이외에 주간과다졸림증과 관련하여 대인 관계적 양상은 아직 연구된 바가 많지 않다. 그러나 Kaneita 등의 연구에서 개인이 주관적으로 지각하는 스트레스는 주간 과다졸림증에 영향을 미치는 다른 변인들을 통제한 후에도 유의한 영향이 있었고, ${ }^{16}$ 대인관계 문제, 이혼 가정과 같은 부 정적인 가정환경이나 일부 사회적 관계를 반영하는 요인들도 주간과다졸림증과 관련이 있었다.711 사회적 관계망과 사회적 지지는 좋은 수면 상태를 위한 요소 중 하나이고, ${ }^{17}$ 사회적 지 지가 높을수록 수면 상태에 대한 불만이 적고 수면의 질이 높 은 것으로 알려져 있다. ${ }^{18}$ 이러한 연구 결과들은 사회적 지지 가 주간과다졸림증의 원인이 될 수 있다는 가능성을 시사하였 다. 그러나 대부분의 연구가 사회인구학적 요인을 통해 상관 관계를 추측하는 연구였고, 현재까지 사회적 지지가 주간과다 졸림증에 미치는 영향을 직접적으로 살펴본 연구는 없었다.

주간과다졸림증은 기억력 저하와 부주의로 인한 업무 수행 능력 저하의 원인이며, 심각할 경우 대인관계를 악화시켜 삶 의 질을 저하시키는 것으로 밝혀졌다. ${ }^{19}$ 선행 연구들에 따르 면 일반적으로 대학생은 수면에 취약한 시기이고 생리적 혹 은 환경적 요인으로 인해 졸림을 많이 경험하지만 국내에서 는 졸림이라는 증상에 대해 주로 수면장애를 가진 환자들을 대상으로 연구가 이루어져 왔다. 또한, 주간과다졸림증에 수
면 부족과 같은 생리적인 원인 외에 다양한 요인들이 존재할 가능성들이 시사되었으나 대부분의 연구가 부족한 수면에 만 초점을 두거나 다양한 요인들을 고려하지 않았다. 따라서 본 연구는 국내 서울 소재의 여자 대학생들을 대상으로 주간 과다졸림증과 수면(주관적으로 지각하는 수면 시간, 불면증 증상), 정서(우울과 불안), 사회적 지지의 관계를 탐색하였다.

\section{방 법}

\section{연구 대상}

본 연구는 서울의 S여자 대학교에 재학 중인 학부생 180 명 을 대상으로 하였다. 연구 대상자에게 설문지를 통해 질문에 응답하도록 하였고 이 중 무응답, 불성실한 응답, 30 대, 학생 외의 직업을 가진 경우는 분석에서 제외하였다. 따라서 최종 분석에 사용된 연구 대상자는 168 명으로, 성별은 모두 여성이 고 평균 연령은 21.64 세 $( \pm 1.66)$ 였다.

\section{측정 도구}

\section{주간과다졸림증}

일상생활에서 졸림을 느끼는 정도를 측정하기 위해 Johns가 개발한 Epworth Sleepiness Scale(ESS)를 국내에서 Cho 등 이 타당화한 질문지를 사용하였다. ${ }^{20,21} \mathrm{ESS}$ 는 총 8문항으로 구성되어 있으며, 책을 읽는 상황, TV를 보는 상황, 대중교통 을 타고 이동하는 상황 등 다양한 상황에서의 졸림 정도를 측 정한다. 각 문항은 4점 척도로 총점이 높을수록 주간에 졸림 을 많이 느끼는 것을 의미한다. 총점의 범위는 0 에서 24점까 지이며, 11 점 이상인 경우를 주간과다졸림증이라고 한다. 본 연구에서의 Cronbach's $\alpha$ 계수는 0.74 였다.

\section{불면증}

불면증 증상의 심각도를 측정하기 위해 Bastien 등이 개발 한 Insomnia Severity Index(ISI)를 Cho가 타당화한 질문지 를 사용하였다. 22,23 ISI는 총 7문항으로 구성되어 있으며 최 근 2주간 불면증이 심한 정도, 현재 수면 양상에 대해 만족하 는 정도, 수면 문제가 낮의 활동을 방해하는 정도, 수면 문제 로 인한 손상 및 수면 문제에 대해 걱정하는 정도를 측정한 다. 각 문항은 5 점 척도로 총점의 범위는 0에서 28점까지이다. 총점이 높을수록 불면증이 심각하다는 것을 의미하며, 본 연 구에서는 0 7점을 정상, 8 14점을 역치하 불면증, 15 21점 을 중등도 불면증, 22 28점을 고도 불면증으로 구분하였다. 본 연구에서의 Cronbach's $\alpha$ 계수는 0.79 였다. 


\section{불안 및 우울}

불안 및 우울을 측정하기 위해 Zigmond와 Snaith가 개발한 Hospital Anxiety and Depression Scale(HADS)을 Oh 등이 번안하여 표준화한 질문지를 사용하였다. ${ }^{24,25} \mathrm{HADS}$ 는 총 14 문항으로, 짝수 7문항은 우울 하위 척도, 홀수 7문항은 불안 하위 척도로 구성되어 있다. 각 문항은 4점 척도로 총점이 높 을수록 우울과 불안 수준이 높다는 것을 의미한다. 우울 하위 척도와 불안 하위 척도 각각의 총점의 범위는 0 에서 21점까 지이며, 각 하위 척도는 총점이 8점 이상일 경우 임상군으로 구분한다. 본 연구에서의 Cronbach's $\alpha$ 계수는 0.85 였다.

\section{사회적 지지}

본 연구에서는 사회적 지지를 받는 정도를 측정하기 위해 Park 이 개발한 Social Support Scale(SSS)를 사용하였다. ${ }^{26} \mathrm{SSS}$ 는 총 25 문항으로, 평가적 지원 6문항, 정서적 지원 7문항, 물질 적 지원 6 문항, 정보적 지원 6 문항의 4 가지 하위 영역으로 구성되어 있다. 각 문항은 5점 척도로 평정하며, 모든 문항을 합산한 총점의 범위는 25점에서 125 점까지이다. 총점이 높 을수록 사회적 지원을 많이 받았다고 지각하는 것을 의미한 다. 본 연구에서의 Cronbach's $\alpha$ 계수는 0.97 이었다.

\section{주관적 수면 시간}

주관적 수면 시간을 측정하기 위해 Roenneberg 등이 개발 한 Munich Chronotype Questionnaire(MCTQ)를 사용하였 다. ${ }^{27} \mathrm{MCTQ}$ 는 총 25 문항으로 실제 수면 시간과 활동 시간을 평일과 휴일로 구분해서 측정한다. MCTQ의 총 수면 시간 (total sleep time)은 침대에 누워 있던 시간(time in bed)에서 잠에 들기까지 걸린 시간(sleep onset latency)과 잠들고 나 서 중간에 깼던 시간(wake after sleep onset)을 제외한 실제
수면 시간으로 산출하게 된다.

\section{자료분석}

본 연구의 모든 분석에는 SPSS 21.0(SPSS Inc., Chicago, $\mathrm{IL}, \mathrm{USA}$ )를 사용하였으며 연구 가설에 대한 분석 방법은 다 음과 같다.

첫째, 연구 대상자의 일반적인 특성을 파악하기 위해 기술 통계와 빈도 분석을 실시하였다. 둘째, 주간과다졸림증과 주 관적 수면, 정서, 사회적 지지의 관계를 알아보기 위해 Pearson's 적률 상관분석을 실시하였다. 셋째, 주간과다졸림증 임상군과 정상군 간의 주관적 수면, 정서, 사회적 지지 수준에 차이가 있는지를 독립 표본 $\mathrm{T}$ 검정을 통해 알아보았다. 넷째, 주간과다졸림증에 가장 많은 영향을 미치는 변인을 탐색적 으로 알아보기 위해 단계적 다중 회귀분석(stepwise multiple regression analysis)을 실시하였다.

\section{결 과}

\section{연구 대상자의 일반적인 특성}

본 연구 대상자는 총 168 명의 여자 대학생으로, 평균 연령은 21.64세 $( \pm 1.66)$ 였다. 본 연구에서 주간과다졸림증 척도(ESS) 로 평가한 주간과다졸림증의 평균 점수는 $8.06( \pm 3.75)$ 이었다. 이 중 11점 이상을 주간과다졸림증 임상군으로 구분한 결과, $23.8 \%(n=40)$ 가 이에 해당했다. 각 집단의 기술 통계는 Table 1 에 제시하였다.

주간과다졸림증 심각도 수준에 따른 집단 간 차이를 독립 표본 T 검정을 통해 분석한 결과, 주관적 수면 시간에서 주간 과다졸림증 임상군과 정상군의 집단 간 차이는 유의미하지 않았지만 불면증, 불안, 우울, 사회적 지지에서 유의미한 집

Table 1. Demographic findings and information of the study sample $(n=128)$

\begin{tabular}{|c|c|c|c|c|}
\hline \multirow{2}{*}{ Variables } & \multirow{2}{*}{ Questionnaire } & \multirow{2}{*}{$\begin{array}{c}\text { EDS }(n=40) \\
M \pm S D\end{array}$} & \multirow{2}{*}{$\begin{array}{c}\text { Non-EDS }(\mathrm{n}=128) \\
\mathrm{M} \pm \mathrm{SD}\end{array}$} & \multirow{2}{*}{$p$-value } \\
\hline & & & & \\
\hline Demographic information & Age & $21.30 \pm 1.36$ & $21.75 \pm 1.73$ & 0.135 \\
\hline \multirow[t]{4}{*}{ Subjective sleep } & $\operatorname{TSTw}(\min )$ & $347.05 \pm 89.87$ & $366.11 \pm 82.43$ & 0.213 \\
\hline & TSTf (min) & $416.80 \pm 96.88$ & $436.40 \pm 87.40$ & $0.230^{*}$ \\
\hline & ISI & $9.63 \pm 4.57$ & $6.98 \pm 4.47$ & $0.001^{*}$ \\
\hline & ISI $>14, \mathrm{n}(\%)$ & $5(12.5)$ & $9(7.0)$ & \\
\hline \multirow[t]{4}{*}{ Mood } & Depression & $7.80 \pm 3.49$ & $5.64 \pm 2.90$ & $<0.001^{*}$ \\
\hline & HADS-D>8, n (\%) & $21(52.5)$ & $36(29.1)$ & \\
\hline & Anxiety & $8.13 \pm 3.98$ & $6.01 \pm 3.37$ & $0.001^{*}$ \\
\hline & HADS-A>8, n (\%) & $19(47.5)$ & $35(27.3)$ & \\
\hline Social support & SSS & $92.88 \pm 19.29$ & $100.63 \pm 15.10$ & $0.009^{*}$ \\
\hline
\end{tabular}

${ }^{*} p<0.01$. EDS: excessive daytime sleepiness, TSTw: total sleep time on workdays, TSTf: total sleep time on freedays, ISI: Insomnia Severity Index, HADS: Hospital Anxiety and Depression Scale, SSS: Social Support Scale 
단 간 차이가 나타났다.

\section{주간과다졸림증과 주관적 수면, 정서, 사회적 지지의 상관관계}

주간과다졸림증과 주관적 수면, 정서, 사회적 지지의 상관 관계는 Table 2에 제시하였다. 그 결과 주관적 수면 시간은 주 간과다졸림증과 유의미한 상관을 보이지 않았다. 그러나 주간 과다졸림증과 불면증 $(p<0.05)$, 불안 $(p<0.01)$, 우울 $(p<0.01)$ 은 정적인 상관을 보였으며 사회적 지지와는 부적인 상관을 보 였다 $(p<0.01)$. 즉, 주간과다졸림증 수준이 높을수록 불면증 심각도, 불안, 그리고 우울의 수준은 높았고 사회적 지지의 수준은 낮았다.

\section{주관적 수면, 정서, 사회적 지지가 주간과다졸림증에 미치는 영향}

본 연구에서는 주관적 수면, 불면증, 우울, 불안, 사회적 지 지 중에서 주간과다졸림증에 가장 많은 영향을 미치는 변인 을 탐색적으로 살펴보고자 하였다. 따라서 평일과 휴일의 주 관적 수면 시간, 불면증, 우울, 불안, 사회적 지지를 독립 변인 으로, 주간과다졸림증을 종속 변인으로 하여 독립 변인의 진 입과 제거를 단계별로 검토하는 단계적 다중 회귀분석(stepwise multiple regression analysis)을 실시하였다.

결과는 Table 3 과 같다. 주관적 수면, 불면증, 불안, 우울, 사회적 지지 중에서 사회적 지지와 불안만이 주간과다졸림증
을 유의미하게 설명할 수 있는 것으로 나타났다 $\left(\Delta \mathrm{R}^{2}=0.088\right.$, $\mathrm{F}=9.037, p<0.001)$. 그중 주간과다졸림증을 가장 잘 설명해 주는 변인은 사회적 지지였고 $(\beta=-0.276, p<0.001)$, 그 다음으 로는 불안이었다 $(\beta=0.161, p<0.05)$.

\section{고 찰}

본 연구는 국내 여자 대학생을 대상으로 주간과다졸림증을 설명할 수 있는 여러 요인 중 주관적 수면, 불면증, 불안, 우 울, 사회적 지지에 대해 탐색해 보았으며, 여러 요인 중에 국 내 여자 대학생의 주간과다졸림증을 가장 잘 설명할 수 있는 요인에 대해 분석하였다. 본 연구의 주요 결과는 다음과 같다.

첫째, 여자 대학생들에게 주간과다졸림증은 주관적으로 지각하는 수면 시간보다 불면증, 우울, 불안, 사회적 지지와 같은 요인들이 더 중요하게 작용할 수 있다는 것을 보여주었 다. 이것은 주간과다졸림증 임상군과 정상군을 비교했을 때 주관적 수면 시간에서 차이가 나지 않는 결과에서도 검증되 었다. 과거에는 야간의 부족한 수면이 낮 동안의 졸림으로 이 어지는 것이 자연스러운 생리적 현상으로 여겨졌고, 이를 근 거로 주간과다졸림증이 발생하는 주요 원인을 수면 부족으 로 가정하였다. 그러나 수면 부족이 주간과다졸림증의 단일 요인이 아닐 가능성이 밝혀져 왔다. 그 예로, 주간과다졸림증 으로 인한 불편감을 경험하는 사람과 그렇지 않은 사람들 간

Table 2. Association between excessive daytime sleepiness and subjective sleep, emotions, social support

\begin{tabular}{|c|c|c|c|c|c|c|c|}
\hline Variable & 1 & 2 & 3 & 4 & 5 & 6 & 7 \\
\hline 1. EDS & 1 & & & & & & \\
\hline 2. TSTw (min) & -0.097 & 1 & & & & & \\
\hline 3. $\operatorname{TSTf}(\mathrm{min})$ & -0.091 & $0.362^{\dagger}$ & 1 & & & & \\
\hline 4. Insomnia & $0.194^{*}$ & $-0.235^{\dagger}$ & $-0.159^{*}$ & 1 & & & \\
\hline 5. Anxiety & $0.240^{\dagger}$ & -0.126 & -0.086 & $0.397^{\dagger}$ & 1 & & \\
\hline 6. Depression & $0.270^{\dagger}$ & -0.085 & -0.026 & $0.387^{\dagger}$ & $0.572^{\dagger}$ & 1 & \\
\hline 7. Social support & $-0.276^{\dagger}$ & 0.138 & 0.002 & $-0.390^{\dagger}$ & $-0.362^{\dagger}$ & $-0.528^{\dagger}$ & 1 \\
\hline M & 8.06 & 361.57 & 431.73 & 8.61 & 6.51 & 6.15 & 98.79 \\
\hline SD & 3.75 & 84.37 & 89.84 & 5.31 & 3.62 & 3.18 & 16.47 \\
\hline
\end{tabular}

${ }^{*} p<0.05,{ }^{\dagger} p<0.01$. EDS: excessive daytime sleepiness, TSTw: total sleep time on work days, TSTf: total sleep time on free days, SD: standard deviation

Table 3. Factors that influenced EDS $(n=168)$

\begin{tabular}{|c|c|c|c|c|c|c|c|}
\hline \multirow{2}{*}{$\begin{array}{c}\text { Dependent } \\
\text { variable }\end{array}$} & \multicolumn{2}{|c|}{ Independent variable } & \multirow{2}{*}{$\beta$} & \multirow{2}{*}{$\mathrm{t}$} & \multirow{2}{*}{$p$-value } & \multirow{2}{*}{$\mathrm{R}^{2}$} & \multirow{2}{*}{$\mathrm{F}$} \\
\hline & Step & Input variable & & & & & \\
\hline \multirow[t]{3}{*}{ EDS } & 1 & Social support & -0.276 & -3.700 & $<0.001^{\dagger}$ & 0.071 & 13.689 \\
\hline & 2 & Social support & -0.218 & -2.746 & $0.007^{\dagger}$ & 0.088 & 9.037 \\
\hline & & Anxiety & 0.161 & 2.030 & $0.044^{*}$ & & \\
\hline Excluded variable & \multicolumn{7}{|c|}{ TSTw, TSTf, Insomnia, Depression } \\
\hline
\end{tabular}

${ }^{*} p<0.05,{ }^{\dagger} p<0.01$. EDS: excessive daytime sleepiness, TSTw: total sleep time on workdays, TSTf: total sleep time on freedays 
에 수면 부족의 정도를 비교했을 때 흥미롭게도 두 집단 간 차이가 없었다. ${ }^{28}$ 또한, 개인이 야간에 취하는 수면의 양에 따 른 주간과다졸림증의 심각도에도 차이가 없었으며, 수면 시 간을 통제한 후에 다른 사회적 혹은 정서적 요소들의 영향이 의미가 있었다는 연구들이 이를 뒷받침한다. ${ }^{15,29}$ 특히 이런 요 인들은 전통적으로 주간과다졸림증과 관련이 높다고 생각되 어 왔던 폐쇄성 수면무호흡증, 혹은 신체 질환이 비교적 적은 여자 대학생 집단에서 더 중요하게 작용할 수 있다는 점을 시 사한다. 또한 본 연구에서 여자 대학생들 중 임상적인 주간과 다졸림증에 해당되는 사람들은 $23.8 \%$ 로, 기존에 밝혀진 유병 률보다 대학생 집단에서 높게 나타난다는 선행 연구와 일치 하였다. ${ }^{30}$ 그러나 본 연구의 표본에서는 불면증의 비율도 비교 적 높았기 때문에(12.5\%), 주관적으로 보고한 수면 시간이 부 정확하게 측정되었을 가능성도 높으며, 주간과다졸림증의 기 저에 주관적으로 지각하는 수면의 양 외에 높은 주간과다졸 림증에 기여를 하는 심리사회학적인 원인을 비롯한 다른 문 제들도 기여했을 가능성을 고려해야 한다.

둘째, 주간과다졸림증 임상군이 정상군에 비해 불면증과 우울, 불안 수준이 더 높았고 개인이 지각하는 사회적 지지의 수준은 낮은 것으로 나타났다. 이는 일반적으로 경험하는 졸 림과 임상적인 졸림을 구별하려는 입장을 지지하며 주간과다 졸림증을 다양한 측면에서 평가할 필요성을 보여준다. 먼저, 불면증을 경험하는 개인은 보통 졸림(sleepiness)보다는 피곤 함(fatigue)을 더 많이 경험한다고 알려져 있다. ${ }^{31}$ 이러한 이유 로 주간과다졸림증과 불면증을 관계가 없다고 보는 입장도 있지만, ${ }^{16}$ 진단 기준에 따르면 불면증은 주간에 다양한 어려 움을 호소하는데, 주간과다졸림증도 그중 하나에 해당한다. 특히, 불면증 환자들은 실제 수면 시간과 주관적 수면 시간이 상이한 경우가 있으며 피곤함을 졸림으로 착각하는 경우가 많다. 본 연구에서도 주간과다졸림증을 호소하는 군 중 불면 증 임상군에 해당하는 비율은 $12.5 \%$ 으로, 정상군에서의 불 면증이 $7.0 \%$ 인 것에 비해 높은 비율을 보여주었다.

뿐만 아니라 주간과다졸림증은 정서적인 문제를 악화시킬 수 있다. 우울증 진단 기준에서 주간과다졸림증이 필수 증상 은 아니지만 우울증 환자의 약 $57.1 \%$ 가 임상적으로 유의하 게 주간과다졸림증을 동반하였고, 두 증상의 기저에 공통적 인 신경전달물질(세로토닌, 모노아민 산화효소)을 공유할 가 능성이 있다. ${ }^{32,33}$ 또한, 본 연구 결과에서는 주간과다졸림증 과 불안과의 관련성도 나타났다. 선행 연구에서 Choueiry 등 은 대학생 집단에서 임상적으로 높은 불안이 불면증과 낮은 수면의 질과 관련이 있으며, ${ }^{30}$ 임상적인 불안 증상을 경험한 대학생의 $50.8 \%$ 는 주간과다졸림증을 경험했다고 보고하였 다. 다른 선행 연구에서는 주간 졸림을 경험하는 집단에서 불
안 증상의 빈도와 강도가 더 심한 양상을 보였다. ${ }^{34}$ 이는 대학 생 집단과 같은 젊은 성인들에서는, 주간과다졸림증이 수면 문제와 직접적인 관련성이 있다기보다는 높은 불안으로 인한 수면의 질 저하가 간접적인 영향을 미친다는 의미가 될 수 있 다. 이러한 연구 결과는 향후 연구에서 주간과다졸림증의 기 제에 대해 수면 상태뿐만 아니라 다차원적인 관점으로 볼 필 요성을 제시한다.

마지막으로 이 연구에서 가장 새로운 결과는 여자 대학생 에게 여러 요인 중 사회적 지지와 불안이 주간과다졸림증에 큰 영향을 미친 것이다. Park에 의하면 사회적 지지는 개인이 사회적인 관계 안에서 물질 또는 정서적으로 얻을 수 있는 긍 정적인 자원이다. ${ }^{26}$ 사회적 지지는 개인에게 정서적인 만족감 과 안정감을 제공할 뿐만 아니라, 건강을 유지할 수 있도록 하 는 보호요인으로 작용한다. 예를 들어, 사회적 지지는 일상에 서 경험하는 스트레스 수준을 조절하며, 같은 스트레스 상황이 더라도 사회적 지지가 높은 사람들은 적절한 수준의 안녕감 을 유지할 수 있다. ${ }^{35}$

사회적 지지는 수면에서도 중요한 역할을 한다. 사회적 관 계를 비롯한 일상생활의 스트레스는 수면 시간보다 수면의 질과 같은 비회복성 수면에 영향을 미친다. ${ }^{36}$ 또한, 주간과다 졸림증을 심하게 경험할수록 사회적인 활동에 더 많은 방해 를 받는다고 알려진 바 있다. ${ }^{34}$ 상대적으로 적은 사회적 활동 은 개인이 경험할 수 있는 사회적 지지의 양을 감소시키는 원 인이 될 수 있다. 따라서 이러한 결과들은 주간과다졸림증에 대한 사회적 지지의 영향을 고려해야 함을 보여준다. 그러나 현재까지 수면에서 사회적 지지의 영향은 일반적인 수면 상 태 혹은 불면증에서 연구되어 왔으며, 주간과다졸림증과 사 회적 지지에 대한 연구들은 없었다. 따라서 향후 연구에서 대 학생 집단과 같은 젊은 성인 중 주간과다졸림증을 경험하는 개인에게 사회적 지지가 미치는 영향 및 역할을 추가적으로 탐색할 필요가 있다.

연구 결과를 종합하여 본 연구의 의의는 다음과 같다. 첫 째, 본 연구는 국내에서 최초로 여자 대학생을 대상으로 주간 과다졸림증 관련 요인을 분석하였으며, 이 집단에서 주간과 다졸림증의 높은 유병률을 확인할 수 있었다. 다양한 연령대 의 집단을 대상으로 주간과다졸림증의 유병률을 확인한 연 구에서 초기 성인기가 주간과다졸림증 비율이 가장 높았으 며 연령이 증가할수록 감소하는 경향을 보였다. 뿐만 아니라, 같은 20 대라도 대학생은 비대학생과 비교하여 신체적, 정신 적 건강 문제에 대한 호소가 더 많고 주간과다졸림증이 더 발 생한다는 연구가 보고되었다. ${ }^{4,37}$ 수면은 일상생활을 유지하 기 위해 필요한 기본적인 요소이며, 특히 대학생은 초기 성인 기로서 이후 수면 습관 및 건강유지에 중요한 시기이다. 그러 
나 현재까지 대학생의 수면 문제에 대해 논할 때 주로 불면증 에 초점을 두었으며, 주간과다졸림증은 심각한 문제로 다뤄 지지 않았다. 따라서 향후 대학생의 주간과다졸림증에 대한 연구 및 개입의 중요성을 시사했다는 점에서 의의를 가진다.

둘째, 본 연구 결과는 여자 대학생의 주간과다졸림증에서 사회적 지지가 중요한 요인으로 작용할 수 있다는 것을 시사 한다. 전체 연령에서 대학생은 기존 주간과다졸림증과 관련 이 높은 기타 수면장애 혹은 신체 질환의 유병률은 낮지만, 그 반면 다양하고 새로운 과업을 맞이하는 시기이며 환경의 변화로 인해 관계 형성에 대한 스트레스를 경험한다. 특히 여 자 대학생은 남자 대학생과 동일한 스트레스 수준에서 보다 높은 심리적인 어려움을 경험하고, 심인성 정신건강 문제를 주로 호소하는 것으로 알려져 있다. ${ }^{38}$

그러나 단순히 스트레스의 정도가 높을 때보다 주변의 사 회적 지지가 부족할수록 정신적인 문제가 더 악화되므로 스 트레스에 대한 사회적 지지의 역할이 강조되고 있다. ${ }^{39}$ 이를 바탕으로 사회적 지지는 개인이 스트레스 상황에서 안녕감을 유지할 수 있는 보호요인으로 여겨지고 있다. ${ }^{35} \mathrm{SeO}$ 등의 연 구에 따르면 스트레스에 대한 대처 기술이 부족하더라도 사회 적 지지가 높을 경우 양호한 정신건강을 유지할 수 있었다. ${ }^{40}$ 뿐만 아니라 사회적 지지는 좋은 수면을 유지하기 위한 역 할을 한다. ${ }^{41}$ 낮은 사회적 지지를 경험하는 사람은 수면이 분 절될 가능성이 높으며, 불면증의 지속에서도 사회적 지지가 중요 요인으로 작용한다고 보고된 바 있다. ${ }^{18,42}$ 따라서 이러 한 결과를 종합하였을 때, 여자 대학생의 주간과다졸림증에 대한 치료적 개입으로 사회적 지지를 활용하는 것이 도움이 될 것이다. 더 나아가, 사회적 지지가 주간과다졸림증에 미치 는 영향을 고려하였을 때, 수면을 한 사람의 내적 과정으로 분석하는 것에 한정되지 않고, 대인관계적인 측면도 강조되 어야 함을 시사한다.

주간과다졸림증은 주의 집중력의 저하, 정서적인 어려움 등을 유발하여 삶의 질을 저하하는 요소이다. 본 연구는 발 생 빈도가 높은 반면 연구는 부족했던 대학생을 대상으로 주 간과다졸림증을 살펴본 것에 의의가 있다. 더 나아가 주간과 다졸림증의 중요 요인을 파악한 것이 의미 있는 결과일 것이다.

이러한 의의에도 후속 연구에서 보완해야 할 점은 다음과 같다. 첫째, 본 연구의 대상은 여성으로만 구성되었다. 일반 적으로 수면 상태에서 생물학적으로 반응하는 뇌 구조에 기 본적인 성차가 있는 것으로 알려져 있다. ${ }^{7}$ 이에 더해 여성이 남성보다 수면 시간의 절대량이 부족하고 이로 인해 다수의 연구에서 여성이 남성보다 수면장애 및 불편감을 더 많이 호 소하는 것으로 알려져 있다. ${ }^{43,44}$ 따라서, 여성이 취약 집단으 로 여겨지지만 비교적 연구가 덜 이루어진 분야에 대해 파악
하고자 하였다는 점에서는 의의가 있지만 보다 정확한 성차 를 파악하고, 결과를 일반화하기 위해서는 추후 연구에서 남 성을 추가적으로 모집하여 비교하는 것이 필요하다. 또한, 연구에 따르면 여성들은 남성과 비교했을 때 스트레스를 대 처하는 방법이 다르다고 밝혀졌다. ${ }^{45}$ 특히, 본 연구에서 주간 과다졸림증과 관련성이 있다고 밝혀진 사회적 지지는 여성 들의 스트레스 반응과 더 밀접하게 관련이 있다는 돌봄 가설 (tend-and-befriend)이 있다는 것을 감안하여, 사회적 지지가 주간적 졸림증에 미치는 영향에서 성별 차이를 추후 연구에 서 탐색해 볼 필요가 있다. ${ }^{45}$

둘째, 다양한 수면 문제의 가능성을 고려하지 못했다는 한 계점이 있다. 우선, 이 연구에서 사용된 ESS는 사용이 간단한 것에 비해 임상적 졸림을 타당하게 측정하여 주간과다졸림 증 수준의 측정 및 임상군 선별에 유용하다고 알려져 있다. ${ }^{20}$ 그러나 회고적 기억에 의존하여 보고한다는 점에서 실제 본 인의 수면 상태를 과소 추정 혹은 과대 추정할 가능성이 있으 며, 주간과다졸림증을 유발하는 폐쇄성 수면무호흡증과 같 은 일차적인 수면 문제에 대한 진단이 불가능하여 연구의 표 본에서 제외할 수 없었다는 한계점이 있다. 또한 피로감과 졸 림은 흔히 혼동되는 증상이기 때문에 개인이 주관적으로 보 고할 때 잘못 지각할 가능성이 있으며, 본 연구에서는 연구 대 상자의 주관적인 수면 시간만을 측정하였다. 따라서 추후 연 구에는 보다 정확한 임상적 주간과다졸림증의 구분뿐만 아 니라 객관적인 수면 시간의 측정을 위해 수면다원검사나 Multiple Sleep Latency Test와 같은 객관적인 검사를 활용할 필 요가 있다.

셋째, 본 연구는 단면 연구로 진행되었으며 연구 대상자의 표본 수가 적어 주간과다졸림증과 변인들 간의 정확한 인과 성을 파악하기에는 어려움이 있다. 또한 본 연구에서 제시한 불면증, 불안, 우울, 사회적 지지와 같은 변수들은 다수의 연 구에서 상호 연관성이 높다고 알려진 변수들이다. 따라서 추 후 연구에서는 보다 많은 표본 수를 대상으로 종단 연구를 통 해 주간과다졸림증과 불면증, 우울, 불안, 사회적 지지의 관 련성을 지속적으로 파악하고, 각 변수들의 상호적인 영향을 탐색해야 한다.

마지막으로, 본 연구 참여자들 중 임상적 불면증 증상을 호 소하는 비율이 높았으며, 이것은 수면제를 복용하는 참여자 였다면 주간과다졸림증에 기여를 했을 가능성도 있다. 본 연 구에서는 수면제 및 타 약물의 복용에 대한 자료를 수집하 지 않았으므로 결과의 조심스러운 해석이 필요하다.

이러한 연구의 한계점에도 불구하고, 본 연구는 여자 대학 생을 대상으로 주간과다졸림증에 영향을 주는 주관적으로 지각하는 수면 이외의 심리 사회학적인 요인들에 분석을 통 
해, 주간과다졸림증의 정서적, 대인관계적인 양상에 대한 고 려가 추후 연구에서도 지속적으로 이루어져야 한다는 결론 을 내릴 수 있다.

\section{REFERENCES}

1. American Sleep Disorders Association. The International Classification of Sleep Disorders: diagnostic and coding manual. Rochester: American Sleep Disorders Association, 1997.

2. Roth T, Roehrs TA. Etiologies and sequelae of excessive daytime sleepiness. Clin Ther 1996;18:562-576; discussion 561.

3. Ford ES, Cunningham TJ, Giles WH, Croft JB. Trends in insomnia and excessive daytime sleepiness among U.S. adults from 2002 to 2012. Sleep Med 2015;16:372-378.

4. Lund HG, Reider BD, Whiting AB, Prichard JR. Sleep patterns and predictors of disturbed sleep in a large population of college students. J Adolesc Health 2010;46:124-132.

5. Park YM, Matsumoto K, Shinkoda H, Nagashima H, Kang MJ, Seo YJ. Age and gender difference in habitual sleep-wake rhythm. Psychiatry Clin Neurosci 2001;55:201-202.

6. Armitage R, Hoffmann RF. Sleep EEG, depression and gender. Sleep Med Rev 2001;5:237-246.

7. Doi Y, Minowa M. Gender differences in excessive daytime sleepiness among Japanese workers. Soc Sci Med 2003;56:883-894.

8. Eun KS, Cha SE. Gender differentials and covariates of sleep time in daily life of Korea. Stat Res 2010;15:82-103.

9. Kim HJ. Survey of the sleep deprivation and effects on cognitive functions in residents and interns of training hospital [dissertation]. Seoul: Ewha Womans University;2008.

10. Shin K, Yi H, Kim J, Shin C. Prevalence and associated factors of excessive daytime sleepiness in adults. J Korean Acad Nurs 2006;36:829-836.

11. Nugent AM, Gleadhill I, McCrum E, Patterson CC, Evans A, MacMahon J. Sleep complaints and risk factors for excessive daytime sleepiness in adult males in Northern Ireland. J Sleep Res 2001;10:69-74.

12. Hara C, Lopes Rocha F, Lima-Costa MF. Prevalence of excessive daytime sleepiness and associated factors in a Brazilian community: the Bambuí study. Sleep Med 2004;5:31-36.

13. Ohayon MM, Caulet M, Philip P, Guilleminault C, Priest RG. How sleep and mental disorders are related to complaints of daytime sleepiness. Arch Intern Med 1997;157:2645-2652.

14. Chellappa SL, Araújo JF. Excessive daytime sleepiness in patients with depressive disorder. Rev Bras Psiquiatr 2006;28:126-129.

15. Breslau N, Roth T, Rosenthal L, Andreski P. Daytime sleepiness: an epidemiological study of young adults. Am J Public Health 1997;87:1649-1653.

16. Kaneita Y, Ohida T, Uchiyama M, et al. Excessive daytime sleepiness among the Japanese general population. J Epidemiol 2005;15:1-8.

17. Nakata A, Haratani T, Takahashi M, et al. Job stress, social support, and prevalence of insomnia in a population of Japanese daytime workers. Soc Sci Med 2004;59:1719-1730.

18. Troxel WM, Buysse DJ, Monk TH, Begley A, Hall M. Does social support differentially affect sleep in older adults with versus without insomnia? J Psychosom Res 2010;69:459-466.

19. El-Ad B, Korczyn AD. Disorders of excessive daytime sleepiness--an update. J Neurol Sci 1998;153:192-202.

20. Johns MW. A new method for measuring daytime sleepiness: the Epworth Sleepiness Scale. Sleep 1991;14:540-545.

21. Cho YW, Lee JH, Son HK, Lee SH, Shin C, Johns MW. The reliability and validity of the Korean version of the Epworth Sleepiness Scale. Sleep Breath 2011;15:377-384.

22. Bastien CH, Vallières A, Morin CM. Validation of the Insomnia Severity Index as an outcome measure for insomnia research. Sleep Med 2001;
2:297-307.

23. Cho YW. Sleep scale and sleep hygiene. J Korean Sleep Research Soc 2004;1:12-23.

24. Zigmond AS, Snaith RP. The hospital anxiety and depression scale. Acta Psychiatr Scand 1983;67:361-370.

25. Oh SM, Min KJ, Park DB. A study on the standardization of the hospital anxiety and depression scale for Koreans-a comparison of normal, depressed and anxious groups. J Korean Neuropsychiatr Assoc 1999; 38:289-296.

26. Park JW. A study to development a scale of social support [dissertation]. Seoul: Yonsei University; 1985:110-115.

27. Roenneberg T, Wirz-Justice A, Merrow M. Life between clocks: daily temporal patterns of human chronotypes. J Biol Rhythms 2003;18:80-90.

28. Bixler EO, Vgontzas AN, Lin HM, Calhoun SL, Vela-Bueno A, Kales A. Excessive daytime sleepiness in a general population sample: the role of sleep apnea, age, obesity, diabetes, and depression. J Clin Endocrinol Metab 2005;90:4510-4515.

29. Choi YK, Lee HJ, Suh KY, Kim L. Relationship between sleep insufficiency and excessive daytime sleepiness. Sleep Med Psychophysiol 2003; 10:93-99.

30. Choueiry N, Salamoun T, Jabbour H, El Osta N, Hajj A, Rabbaa Khabbaz L. Insomnia and relationship with anxiety in university students: a cross-sectional designed study. PLoS One 2016;11:e0149643.

31. Riedel BW, Lichstein KL. Insomnia and daytime functioning. Sleep Med Rev 2000;4:277-298.

32. Ojeda DA, Niño CL, López-León S, Camargo A, Adan A, Forero DA. A functional polymorphism in the promoter region of MAOA gene is associated with daytime sleepiness in healthy subjects. J Neurol Sci 2014; 337:176-179.

33. Chellappa SL, Schröder C, Cajochen C. Chronobiology, excessive daytime sleepiness and depression: is there a link? Sleep Med 2009;10:505-514.

34. Kim PY, Ryu SH. Relationships between sleepiness, stress response, and anxiety symptoms of students in a university. Anxiety Mood 2014;10: 137-142.

35. Cohen S, Wills TA. Stress, social support, and the buffering hypothesis. Psychol Bull 1985;98:310-357.

36. Kang SG, Yoon HK, Ham BJ, et al. Effects of minor stressful events on sleep in college students. Sleep Med Psychophysiol 2002;9:48-55.

37. Tsai LL, Li SP. Sleep patterns in college students: gender and grade differences. J Psychosom Res 2004;56:231-237.

38. Burt VK, Stein K. Epidemiology of depression throughout the female life cycle. J Clin Psychiatry 2002;63 Suppl 7:9-15.

39. Park YR, Jang EH. Impact of stress on depression among university students: testing for moderating effect of social support. Korean J Adult Nurs 2013;25:549-558.

40. Seo M, Choi BY, Jo HI. The effect of life stress, stress coping, and social support on mental health. Korea J Couns 2006;7:271-288.

41. Hanson BS, Ostergren PO. Different social network and social support characteristics, nervous problems and insomnia: theoretical and methodological aspects on some results from the population study 'men born in 1914,' Malmö, Sweden. Soc Sci Med 1987;25:849-859.

42. Jansson M, Linton SJ. Psychosocial work stressors in the development and maintenance of insomnia: a prospective study. J Occup Health Psychol 2006;11:241-248.

43. Arber S, Bote M, Meadows R. Gender and socio-economic patterning of self-reported sleep problems in Britain. Soc Sci Med 2009;68:281-289.

44. Maume DJ, Sebastian RA, Bardo AR. Gender differences in sleep disruption among retail food workers. American Sociol Rev 2009;74:9891007.

45. Taylor SE, Klein LC, Lewis BP, Gruenewald TL, Gurung RA, Updegraff JA. Biobehavioral responses to stress in females: tend-and-befriend, not fight-or-flight. Psychol Rev 2000;107:411-429. 